Correction

\title{
Correction: Ducey et al. Differences in Microbial Communities and Pathogen Survival Between a Covered and Uncovered Anaerobic Lagoon. Environments, 2019, 6, 91
}

\author{
Thomas F. Ducey ${ }^{1, *(\mathbb{D}}$, Diana M. C. Rashash ${ }^{2}$ and Ariel A. Szogi ${ }^{1}$ (1) \\ 1 Coastal Plains Soil, Water, and Plant Research Center, Agricultural Research Service, USDA, \\ Florence, SC 29501, USA; ariel.szogi@ars.usda.gov \\ 2 North Carolina Cooperative Extension Service, Jacksonville, NC, 28540, USA; diana_rashash@ncsu.edu \\ * Correspondence: thomas.ducey@ars.usda.gov; Tel.: +1-843-669-5203
}

The authors would like to correct the published article [1]:

On page 11, Figure 7C,D should be changed from:
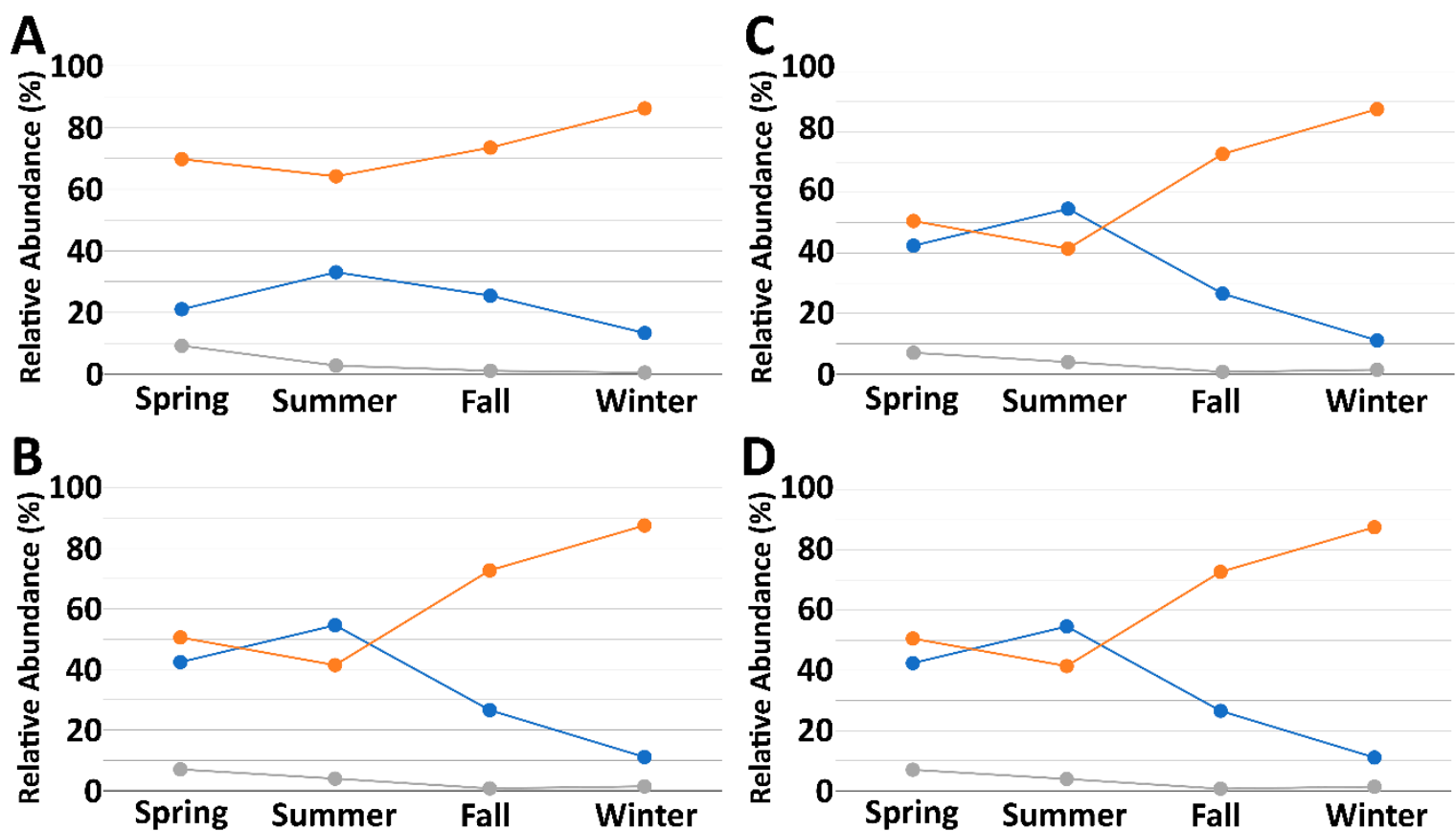

Hydrogenotrophic

Acetoclastic

Methylotrophic

Figure 7. Relative abundance of classified operational taxonomic units (OTUs) potentially involved in methanogenic pathways. (A) Open Lagoon; (B) Open House; (C) Covered Lagoon; (D) Covered House.

to the following correct version: 

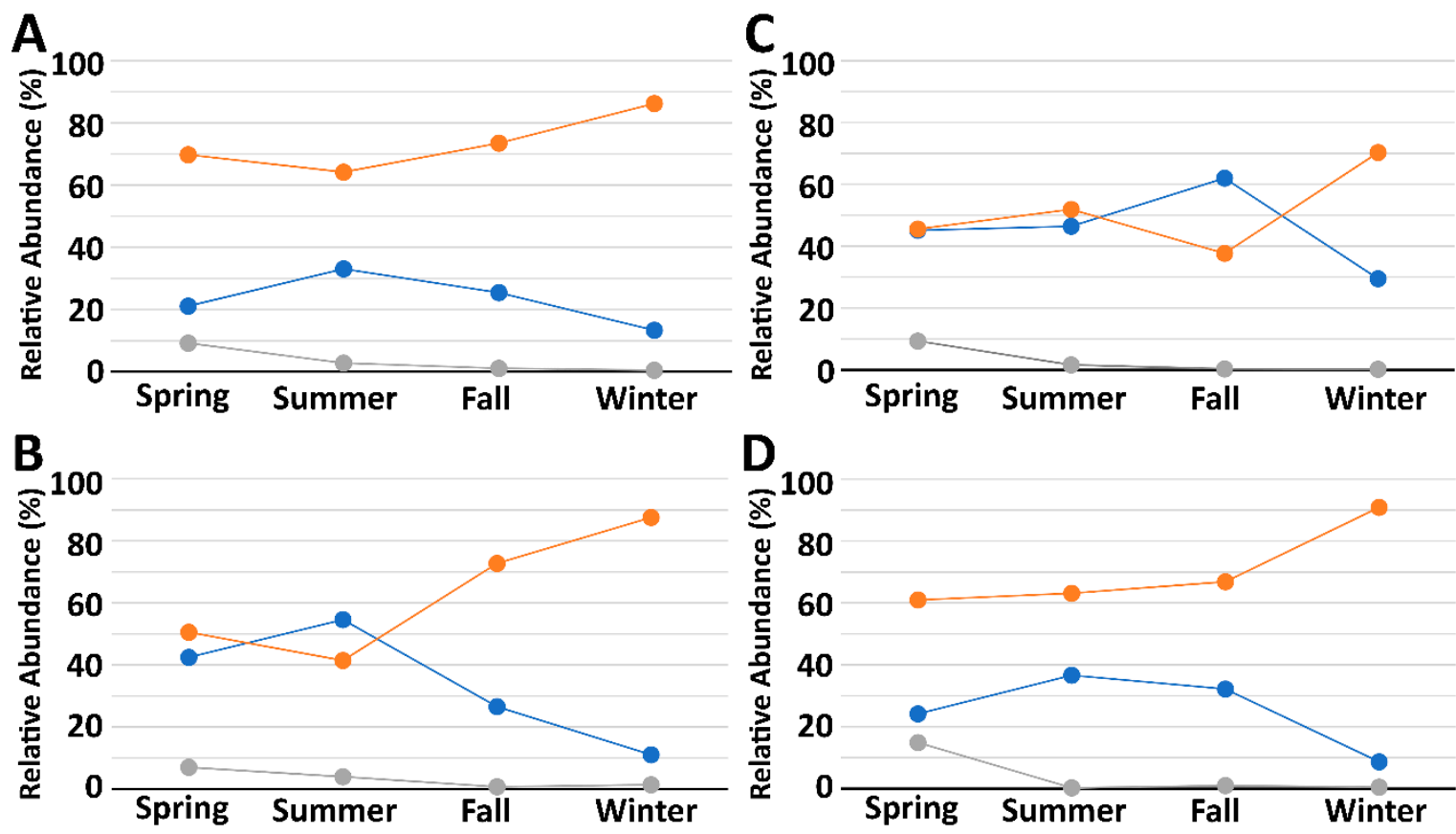

Hydrogenotrophic Acetoclastic Methylotrophic

Figure 7. Relative abundance of classified operational taxonomic units (OTUs) potentially involved in methanogenic pathways. (A) Open Lagoon; (B) Open House; (C) Covered Lagoon; (D) Covered House.

The authors apologize for any inconvenience this has caused to the readers. The changes do not affect the scientific results of this paper. The manuscript will be updated, and the original version will remain online on the article webpage, with a reference to this Correction.

\section{References}

1. Ducey, T.F.; Rashash, D.M.C.; Szogi, A.A. Differences in Microbial Communities and Pathogen Survival Between a Covered and Uncovered Anaerobic Lagoon. Environments 2019, 6, 91. [CrossRef] 